EFFECTIVENESS BULLETIN

\title{
Interventions for the treatment and management of chronic fatigue syndrome/myalgic encephalomyelitis
}

\author{
A-M Bagnall, P Whiting, R Richardson, A J Sowden
}

Qual Saf Health Care 2002;11:284-288

The research evidence on the effectiveness of interventions for the treatment and management of chronic fatigue syndrome/myalgic encephalomyelitis (CFS/ME) published in a recent issue of Effective Health Care is reviewed.

See end of article for authors' affiliations

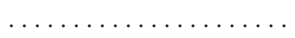

Correspondence to: Anne-Marie Bagnall, NHS Centre for Reviews and Dissemination, University of York, York YO 10 5DD

UK; amb13@york.ac.uk
$\mathrm{T}$ his article summarises the research evidence presented in a recent issue of Effective Health Care on interventions for the treatment and management of chronic fatigue syndrome/ myalgic encephalomyelitis (CFS/ME). ${ }^{1}$ It provides an overview of the evidence from a systematic review of randomised controlled trials commissioned by the Department of Health. ${ }^{2}$ The results of the systematic review were found to be similar to those of another systematic review carried out in the USA at the same time, ${ }^{3}$ and the two have been combined and published together in $2001 .^{4}$

\section{BACKGROUND}

Chronic fatigue syndrome (CFS) consists of a range of symptoms including fatigue, headaches, sleep disturbances, difficulties with concentration, and muscle pain. The defining characteristic has been reported to be debilitating fatigue. ${ }^{5-7}$ Children and adults present with similar symptoms. ${ }^{8}$ Myalgic encephalomyelitis (ME) is sometimes reported to be a separate syndrome from CFS, characterised by muscle weakness, pain and neurological disturbance. ${ }^{9}$ It has been suggested that CFS and ME are part of a group of similar symptom complexes such as postviral fatigue syndrome, fibromyalgia and neurasthenia. ${ }^{6} \mathrm{ME}$ is sometimes diagnosed in people with these symptom complexes in the UK, but is not commonly diagnosed in other countries such as the USA. ${ }^{10}$ In this review the condition will be referred to as CFS/ME.

The cause of CFS/ME remains unknown, although various hypotheses have been suggested that include one or more of the following factors: immunological, viral, psychological and neuroendocrine. Diagnosis is based entirely on symptoms reported by the patient. Definitions commonly used tend to be research criteria. ${ }^{11}$ Two frequently used definitions for CFS are the UK (Oxford) criteria $^{5}$ and the US Centers for Disease Control and Prevention criteria. ${ }^{6}$ Both state that debilitating fatigue must be present for at least 6 months, that there is some functional impairment, and that these have not been caused by any other identifiable clinical condition. The definitions differ, however, in the number and severity of other symptoms that must be present. In practice a clinical assessment is used which aims to increase the probability of a correct diagnosis of CFS/ME and to rule out other conditions. ${ }^{11}$ This involves taking a full clinical history, a mental health evaluation, sleep evaluation, and a physical examination. It is recommended that a series of basic screening tests be undertaken to exclude other conditions that can present as fatigue. ${ }^{11}$

Estimates of prevalence vary, and may be attributed to the diversity in diagnostic criteria and to variations in the extent to which alternative medical and psychiatric diagnoses have been excluded. One small UK study reported that the point prevalence of CFS was $0.6 \%$ (95\% confidence interval 0.2 to 1.5 ) using the UK (Oxford) criteria. ${ }^{12}$ A larger UK study reported a prevalence ranging from $0.5 \%$, when comorbid psychological disorders were excluded, to $2.6 \%$ when they were not. ${ }^{13}$ Onset is most commonly reported to be from the early twenties to mid-forties. It is reported to be approximately twice as common in women as in men, affects all social classes to a similar extent, and affects all ethnic groups. ${ }^{11}$ Based on an estimate of adult population prevalence of $0.4 \%$, the CFS/ME Working Group reported that a general practice with a population of 10000 patients is likely to have $30-40$ patients with CFS/ME, about half of whom may need input from specialist services. ${ }^{11}$

It is generally recognised that prognosis is variable. Many patients improve quite quickly. However, in those who do not improve quickly, the illness can persist for a long time. The prognosis tends to be worse for severely ill patients than for less severely ill patients. ${ }^{11}$ The findings from prospective natural history studies are varied. ${ }^{3}$ At 12-18 months, rates of self-reported global improvement in symptoms range from $11 \%$ to $64 \%$ and rates of self-reported worsening of symptoms from $15 \%$ to $20 \%$.

\section{CURRENT SERVICE PROVISION}

The recent CFS/ME Working Group Report ${ }^{11}$ stated that the provision of services specifically designed for patients with CFS/ME is limited in some areas and non-existent in others. While patients have access to the normal range of primary, secondary and tertiary care services, few are tailored to this patient group. Specialist services for children and young people, including inpatient facilities, are limited to a few nationwide. Referrals from primary care are to one or more specialists such as general physicians, immunologists, neurologists, haematologists, and psychiatrists. The CFS/ME Working Group Report suggests that the lack of locally based specialist services may be a problem for patients who need 


\begin{tabular}{|c|c|c|c|c|c|}
\hline Treatment & $\begin{array}{l}\text { Duration of follow } \\
\text { upt (weeks) }\end{array}$ & $\begin{array}{l}\text { Number of } \\
\text { participants }\end{array}$ & Outcomes investigated & Any effect & $\begin{array}{l}\text { Overall } \\
\text { effect }\end{array}$ \\
\hline \multicolumn{6}{|l|}{ Behavioural } \\
\hline $\mathrm{GET}^{26}$ & 12 & 66 & PH; PS; LAB; QOL & + & + \\
\hline $\mathrm{GET}^{27}$ & $52(26)$ & 148 & $\mathrm{PH}$; $\mathrm{PS}$; QOL & + & + \\
\hline GET \& fluoxetine ${ }^{28}$ & 26 & 136 & PH; PS; QOL & + & $<>$ \\
\hline $\mathrm{CBT}^{20}$ & 26 (and 5 years) & 60 & PH; PS; QOL & + & + \\
\hline $\mathrm{CBT}^{21}$ & $61(35)$ & 270 & $\mathrm{PH} ; \mathrm{PS} ; \mathrm{QOL}$ & + & + \\
\hline $\mathrm{CBT}^{19}$ & 52 & 60 & PH; PS; QOL & + & + \\
\hline $\mathrm{CBT}+\mathrm{DLE}^{22}$ & $30(16)$ & 90 & PH; PS; LAB; QOL & + & $<>$ \\
\hline \multicolumn{6}{|l|}{ Immunological } \\
\hline Immunoglobulin ${ }^{31}$ & $26(13)$ & 71 & PH & + & + \\
\hline Immunoglobulin ${ }^{30}$ & 21 & 30 & $\mathrm{PH} ; \mathbf{L A B} ; \mathrm{QOL}$ & + & $<>$ \\
\hline Immunoglobulin ${ }^{29}$ & $26(13)$ & 49 & PS; QOL & + & $<>$ \\
\hline Immunoglobulin ${ }^{33}$ & $26(13)$ & 99 & PH; PS; LAB; QOL & $<>$ & $<>$ \\
\hline Gammaglobulin ${ }^{32}$ & 17 & 19 & QOL & + & + \\
\hline Ampligen $^{34}$ & 26 & 92 & $\mathrm{RU}$; PH; PS & + & + \\
\hline Terfenadine $^{35}$ & 9 & 30 & $\mathrm{PH} ; \mathrm{QOL}$ & $<>$ & $<>$ \\
\hline \multicolumn{6}{|l|}{ Antiviral } \\
\hline Alpha interferon ${ }^{37}$ & 12 & 30 & LAB; QOL & + & $<>$ \\
\hline Interferon ${ }^{36}$ & $52(12)$ & 20 & $\mathrm{PH}$ & + & + \\
\hline Aciclovir $^{38}$ & $18(13)$ & 27 & PH; PS; LAB; QOL & - & $<>$ \\
\hline Ganciclovir $^{39}$ & 26 & 11 & QOL & $<>$ & $<>$ \\
\hline \multicolumn{6}{|l|}{ Pharmacological } \\
\hline Hydrocortisone ${ }^{43}$ & 9 & 32 & PH; QOL & + & $<>$ \\
\hline Hydrocortisone ${ }^{44}$ & 12 & 70 & PH; PS; QOL & + & $<>$ \\
\hline Fludrocortisone $e^{46}$ & $11(9)$ & 100 & $\mathrm{PH} ; \mathrm{PS} ; \mathrm{LAB} ; \mathrm{QOL}$ & $<>$ & $<>$ \\
\hline Fludrocortisone $e^{45}$ & 18 & 25 & $\mathrm{PH} ; \mathrm{PS} ; \mathrm{QOL}$ & $<>$ & $<>$ \\
\hline Fluoxetine $e^{41}$ & $12(8)$ & 107 & PH; PS; QOL & $<>$ & $<>$ \\
\hline Phenelzine ${ }^{40}$ & 6 & 24 & PH; PS; QOL & $<>$ & $<>$ \\
\hline Moclobemide ${ }^{42}$ & 6 & 90 & PH; PS; LAB; QOL & $<>$ & $<>$ \\
\hline Sulbutiamine $\mathrm{e}^{48}$ & 4 & 326 & $\mathrm{PH} ; \mathrm{QOL}$ & $<>$ & $<>$ \\
\hline Galanthamine hydrobromide ${ }^{47}$ & 2 & 49 & PH; PS; QOL & $<>$ & $<>$ \\
\hline Oral NADH ${ }^{50}$ & 12 & 26 & QOL & + & + \\
\hline Growth hormone ${ }^{49}$ & 12 & 20 & PH & $<>$ & $<>$ \\
\hline \multicolumn{6}{|l|}{ Supplements } \\
\hline Essential fatty acids $* 52$ & 13 & 63 & LAB; QOL & + & + \\
\hline Essential fatty acids $\star 51$ & 13 & 50 & PS; QOL & + & $<>$ \\
\hline Magnesium ${ }^{53}$ & 6 & 34 & $\mathrm{PH} ; \mathrm{PS}$; LAB; QOL & + & + \\
\hline Liver extract ${ }^{54}$ & 2 & 15 & $\mathrm{PH} ; \mathrm{PS} ; \mathrm{QOL}$ & $<>$ & $<>$ \\
\hline General supplements ${ }^{55}$ & 7 & 12 & PH & + & + \\
\hline \multicolumn{6}{|l|}{ Complementary/alternative } \\
\hline Any homoeopathic remedy ${ }^{58}$ & 26 & 104 & PH; PS & + & $<>$ \\
\hline Any homoeopathic remedy ${ }^{57}$ & 52 & 64 & QOL & + & + \\
\hline Massage therapy $y^{56}$ & 5 & 20 & $\mathrm{PH} ; \mathrm{PS}$; LAB & + & + \\
\hline \multicolumn{6}{|l|}{ Multi-treatment } \\
\hline Multi-treatment ${ }^{59}$ & 13 & 72 & $\mathrm{PH} ; \mathrm{QOL}$ & + & + \\
\hline
\end{tabular}

access to services but are unable to reach them, and for commissioners who wish to reduce the cost of out of area treatments.

\section{TREATMENT AND MANAGEMENT}

A number of interventions have been used in the treatment and management of CFS/ME. The CFS/ME Working Group Report $^{2}$ identified three therapeutic strategies as potentially beneficial: cognitive behavioural therapy (CBT), graded exercise therapy (GET), and pacing.

The evidence for CBT and GET comes from randomised controlled trials while that for pacing comes from patient reports and clinical experience. The report called for more research, particularly into pacing. The Department of Health has now asked the Medical Research Council to develop a broad strategy for advancing biomedical and health services research on CFS/ME (http://www.doh.gov.uk/cmo/CFS/ MEmereport/response.htm).

An overview of the included studies and main findings from the systematic review is presented in table 1 . To provide an overall estimate of whether each study found a positive, negative or no effect of the intervention, all studies were classified according to two separate methods: whether the study showed any effect of the intervention and whether it showed any overall effect.

\section{Interpreting the findings}

Some of the interventions have been evaluated in only one or two studies, which may limit the generalisability of the findings. Many studies had relatively small sample sizes, did not use standardised outcome measures, and failed to use an intention-to-treat analysis. Many of the data presented in the studies were limited and, because of differences between studies (for example, outcomes reported, types of data presented and interventions evaluated), it was not possible to calculate pooled summary statistics. Also of importance are the inclusion criteria specified in some trials, such as participants being eligible if they could physically get to the clinic. Those people who were unable to walk or to get out of bed were excluded and so it has not been possible to assess 
whether the interventions investigated would be effective, ineffective, or even hazardous for a more severely disabled group of people. Uncontrolled studies of interventions for severely disabled people with CFS/ME are reported to have shown no evidence of harm. ${ }^{14-16}$ However, these studies do not form part of the evidence base for this review.

In some of the trials, limited information was provided for patients who were ineligible or about the baseline functioning of many of those who were included. It is therefore difficult to extrapolate the findings to other people with CFS/ME. In those trials that did report baseline functioning, the majority of participants were unable to take part in full time employment. Another limitation of most of the trials was the duration of follow up. The relapsing nature of the condition suggests that follow up should continue for an additional 6-12 months (at least) after the intervention period has ended to confirm whether any improvement persists for a relevant period of time.

Many different outcomes were reported and were measured using a variety of scales. Outcomes such as "improvement", where participants were asked to rate themselves as better or worse after the intervention, were frequently reported. However, the person may feel better able to cope with daily activities because they have reduced their expectations of what they should achieve, rather than because they have made any recovery as a result of the intervention. A more objective measure of the effect of any intervention would be whether participants had increased their working hours, returned to work, or increased their physical activities, and these outcomes were evaluated in some studies.

Some interventions have been evaluated using nonrandomised controlled trials, including osteopathy, modified CBT (based on coping within limits set by symptoms), and other multi-treatment approaches. These have been reviewed elsewhere and have yet to be evaluated in randomised controlled trials. ${ }^{2}$ Randomised controlled trials are also needed to evaluate the effectiveness of pacing. Pacing is an energy management strategy in which patients are encouraged to achieve an appropriate balance between rest and activity. This usually involves living within physical and mental limitations imposed by the illness, and avoiding activities to a degree that exacerbates symptoms or interspersing activity with periods of rest. ${ }^{11}$ An understanding of the underlying mechanisms of CFS/ME is likely to aid in the development of effective treatment or management programmes.

\section{Behavioural interventions}

Recommendations about the use of behavioural interventions such as CBT can be misinterpreted when the perceived suggestion is that CFS/ME is a psychological condition. However, conclusions about the cause of the condition cannot be drawn from the fact that certain treatments may be effective. Behavioural interventions, and CBT in particular, have been used effectively in other physical illnesses such as heart disease ${ }^{17}$ and chronic low back pain. ${ }^{18}$

Four randomised controlled trials evaluated weekly or biweekly sessions of CBT. CBT was compared with routine medical care in one trial $(\mathrm{n}=60),{ }^{19}$ with relaxation in a second trial $(\mathrm{n}=60),{ }^{20}$ and with natural course (control) in a third $(n=270) .^{21}$ The fourth trial $(n=90)$ compared four groups: CBT plus placebo injections; CBT plus leukocyte extract (a fraction of blood containing white blood cells); a control clinic plus leukocyte extract; and a control clinic plus placebo injections. ${ }^{22}$

Participants who received combined leukocyte extract and CBT showed a beneficial effect on general health compared with the other three groups. ${ }^{22}$ The remaining three trials reported a beneficial effect of CBT when compared with control groups. ${ }^{19-21}$ Two randomised controlled trials found a significant global improvement at follow up. ${ }^{19}{ }^{20}$ All but the combined leukocyte extract/CBT study also found significant improvements in physical functioning and fatigue. Neither of the two studies that assessed depression found any differences between groups. ${ }^{19}{ }^{20}$ One of these trials also followed patients for 5 years after the intervention ${ }^{20}$ and found that global improvement was greater in the intervention group, as was the mean number of hours worked per week and the proportion of participants who completely recovered (the definition of "completely recovered" was based on fatigue and physical functioning scores as well as UK (Oxford) CFS criteria). ${ }^{23}$ However, no significant differences were reported between the groups for individual outcomes of physical functioning, fatigue, general health, symptoms, relapses, or the proportion of participants that no longer met the UK (Oxford) criteria for CFS.

Two randomised controlled trials of CBT in primary care are reported to be ongoing. ${ }^{24} 25$

The studies evaluating CBT reported no adverse effects of the intervention except in one trial two participants dropped out of the CBT group because they felt that a deterioration in their symptoms was due to the intervention. ${ }^{19}$ A second randomised controlled trial reported dropout rates of $20-35 \%$ in all three intervention groups, with the highest rates in the CBT group, but the reasons for the dropouts were not reported. $^{21}$

The effects of GET were investigated in three randomised controlled trials $(n=66, n=148$ and $n=136)$, two of which found overall beneficial effects. ${ }^{26}{ }^{27}$ The third found some beneficial effects. ${ }^{28}$ When exercise was combined with fluoxetine there was no additional effect. ${ }^{28}$ One trial assessed different interventions to encourage graded exercise and found benefits from GET when compared with standardised medical care for all outcomes investigated. ${ }^{27}$ The studies did not report any specific adverse effects of GET although two studies did report withdrawals that may have been related to adverse effects of the intervention.

\section{Immunological interventions}

Five randomised controlled trials investigated the effects of immunoglobulin G (an antibody fraction of blood); two found some positive effect $(n=30, n=49)^{29}{ }^{30}$ and two found an overall beneficial effect $(n=19, n=71) .{ }^{31}$ One was conducted in young people aged under $18 .^{31}$ The fifth and largest $(n=99)$ found no effect of treatment. ${ }^{33}$

One randomised controlled trial evaluated ampligen $(n=92)$ and found an overall beneficial effect. ${ }^{34}$ In this trial participants were grouped according to whether they had evidence of human herpes virus 6 (HHV-6) infection and no differences were found between the groups in response to ampligen. Another trial which assessed the combined effect of leukocyte extract and CBT $(n=90)$ found no effect of leukocyte extract on its own but found a beneficial effect on general health in the group receiving both leukocyte extract and $\mathrm{CBT}^{22}$ A third trial which evaluated the antihistamine terfenadine $(n=30)$ found no beneficial effects. ${ }^{35}$

Some severe adverse effects were noted in participants in the immunological intervention groups. Two of 99 patients had to withdraw from immunoglobulin treatment due to severe constitutional symptom reactions. ${ }^{33}$ One recipient also withdrew because of mild but transient liver failure, ${ }^{29}$ and phlebitis has also been found with immunoglobulin infusions. ${ }^{29}$ It should be noted that immunoglobulins and leukocyte extract are blood products and there are known risks associated with their use, such as the possible transfer of infectious diseases.

\section{Antiviral interventions}

Two randomised controlled trials evaluated interferon, one of which found an overall beneficial effect $(n=20)$ and the other reported only within group differences and so no conclusion 
can be drawn from this study. ${ }^{36}{ }^{37}$ The effect of aciclovir was investigated in one small trial $(n=27)$ and a negative effect was reported for anxiety, depression and confusion with the control group showing a greater improvement in symptoms than the treatment group. ${ }^{38}$ Another small randomised controlled trial investigated the effects of ganciclovir $(n=11)$ and found no significant differences between the intervention and control groups. ${ }^{39}$ Three patients had to withdraw from aciclovir treatment due to reversible renal failure. ${ }^{38}$ In the ganciclovir study two of the 11 participants who were undergoing right ventricular endomyocardial biopsies experienced serious pericardial bleeding and so the study was ended prematurely. ${ }^{39}$

\section{Pharmacological interventions Antidepressants}

The effects of antidepressants were investigated in two randomised controlled trials $(n=24, n=107)$. No benefit was found in patients with CFS/ME from treatment with antidepressants (either in treating symptoms of depression or any of the other outcome measures reported).$^{40}{ }^{41}$ The trial of fluoxetine $^{41}$ also reported no differences in response between depressed and non-depressed participants. One trial $(n=90)$ investigated the effect of moclobemide (a monoamine oxidase inhibitor) and found no benefit of treatment. ${ }^{42}$ This trial also found no differences in response between those with major depression or general psychological distress and those without, or between those with reduced immune responses and those without. ${ }^{42}$

\section{Corticosteroids}

The effects of steroid treatment were investigated in four randomised controlled trials. ${ }^{43-46}$ Two of these trials evaluated hydrocortisone $(n=70, n=32)$ and both reported some beneficial effect. ${ }^{43}{ }^{44}$ The other two trials assessed fludrocortisone $(n=25, n=100)$ and did not find any beneficial effects. ${ }^{45}{ }^{46}$ One trial assessed participants who had been ill for $\geqslant 3$ years separately from those who had been ill for $<3$ years. No differences in response to fludrocortisone between the two groups were reported. ${ }^{46}$

\section{Anticholinergic agents}

Two studies evaluated anticholinergic agents (drugs which inhibit the neurotransmitter acetylcholine at neuromuscular junctions, $n=49$ and $n=326)^{47} 48$ and reported no significant effects of the intervention.

\section{Other pharmacological agents}

One study assessed the growth hormone genotropin $(n=20)$ and found no significant effects of the intervention. ${ }^{49}$ Oral nicotinamide adenine dinucleotide (NADH) led to a greater improvement in symptoms (the only outcome investigated) in the intervention group compared with the control group in one small randomised controlled trial $(n=26) .^{50}$

Adverse events serious enough to cause withdrawal from the studies occurred with fludrocortisone, ${ }^{46}$ moclobemide, ${ }^{42}$ sulbutiamine, ${ }^{48}$ galanthamine hydrobromide, ${ }^{47}$ phenelzine, ${ }^{40}$ and fluoxetine. ${ }^{41}$

\section{Supplements}

Two randomised controlled trials investigated the effect of essential fatty acid supplements. One $(n=50)$ reported some positive effects ${ }^{51}$ and another $(n=63)$ reported an overall beneficial effect. ${ }^{52}$ Magnesium supplements were found to have an overall beneficial effect in one small trial $(n=34) .{ }^{53}$ One very small randomised controlled trial $(n=15)$ of liver extract reported no beneficial effects. ${ }^{54}$ Another trial $(n=12)$ evaluated general supplements and found no effect. ${ }^{55}$ The randomised controlled trial of magnesium supplements reported that two participants left the intervention group after experi- encing a generalised rash..$^{53}$ The other studies did not report any adverse effects.

\section{Complementary/alternative interventions}

An overall beneficial effect of massage therapy was found in one small randomised controlled trial $(n=20) .{ }^{56}$ Two trials assessed the effectiveness of homoeopathy..$^{58}$ One large trial $(\mathrm{n}=104)$ found a positive effect (preliminary results) ${ }^{58}$ and the second $(n=64)$ found an overall positive effect. ${ }^{57}$ There were no reports of adverse events in any of these studies.

\section{Multi-treatment}

An overall beneficial effect on a range of symptoms was found in a randomised controlled trial $(n=72)$ of a symptom based multi-treatment approach in patients with CFS/ME and fibromyalgia. ${ }^{59}$ This programme involved treating specific patient symptoms with a variety of medications. All patients in both the control and intervention groups also received nutritional supplements.

\section{IMPLICATIONS}

- A total of 38 randomised controlled trials have investigated the effectiveness of seven different categories of intervention: behavioural, immunological, antiviral, pharmacological, supplements, complementary/alternative, and multitreatment.

- Overall, the interventions had mixed results in terms of effectiveness. All conclusions about effectiveness should be considered together with the methodological inadequacies in some of the studies.

- Interventions which have shown evidence of effectiveness include cognitive behavioural therapy and graded exercise therapy.

- There is insufficient evidence about how subgroups of patients may respond differently to treatments and further studies investigating additional subgroups are needed.

- In some of the studies bed or wheelchair restricted patients and children have been excluded, which raises questions about the applicability of findings to all people with CFS/ME.

- Immunoglobulin is the only intervention that has been investigated in young people. Two studies of CBT in children aged 10-18 are ongoing, one of which is of family focused CBT ( $G$ Bleijenberg, personal communication, 10 March 2001). ${ }^{60}$

- There is insufficient evidence for additive or combined effects of treatments where more than one treatment is used.

- Future research could usefully compare CBT and GET. A study comparing the effects of CBT and GET is ongoing in patients with chronic fatigue ( $27 \%$ have a diagnosis of CFS/ ME) (L Darbishire, personal communication, 17 March 2001).

- Future research needs to combine scientific rigour with patient acceptability and good quality research is needed to evaluate the effectiveness of pacing, ideally in comparison with CBT and GET. The large number of outcome measures used makes standardisation of outcomes a priority for future research.

\section{Authors' affiliations}

A-M Bagnall, P Whiting, R Richardson, A J Sowden, NHS Centre for Reviews and Dissemination, University of York, York YO10 5DD, UK

\section{REFERENCES}

1 NHS Centre for Reviews and Dissemination. Interventions for the management of CFS/ME. Effective Health Care 2002;7. 
2 NHS Centre for Reviews and Dissemination. A systematic review of interventions for the treatment and management of chronic fatigue syndrome and/or myalgic encephalomyelitis. York: University of York (in preparation).

3 Mulrow CD, Ramirez G, Cornell JE, et al. Defining and managing chronic fatigue syndrome. Rockville, MD: Agency for Healthcare Research and Quality, 2001

4 Whiting $\mathbf{P}$, Bagnall AM, Sowden A, et al. Interventions for the treatment and management of chronic fatigue syndrome: a systematic review. JAMA 2001;286:1360-8.

5 Sharpe M, Archard L, Banatvala J. A report: chronic fatigue syndrome: guidelines for research. J R Soc Med 1991;84:118-21.

6 Fukuda K, Straus SE, Hickie I, et al. The chronic fatigue syndrome: a comprehensive approach to its definition and study. Ann Intern Med 1994;121:953-9.

7 Holmes G, Kaplan J, Gantz N, et al. Chronic fatigue syndrome: a working case definition. Ann Intern Med 1988;108:387-9.

8 Joyce J, Hotopf $M$, Wessely S. The prognosis of chronic fatigue and chronic fatigue syndrome: a systematic review. Q J Med 1997;90:223-33.

9 Dowsett EG, Ramsay AM, McCartney RA, et al. Myalgic encephalomyelitis: a persistent enteroviral infection? Postgrad Med J 1990;66:526-30.

10 Wessely S, Hotopf M, Sharpe M. Chronic fatigue and its syndromes. New York: Oxford University Press, 1999

11 Department of Health. A report of the CFS/ME Working Group: report to the Chief Medical Officer of an Independent Working Group. London: Department of Health, 2002

12 Lawrie S, Pelosi A. Chronic fatigue syndrome in the community: prevalence and associations. Br J Psychiatry 1995;166:793-7.

13 Wessely S, Chalder T, Hirsch S, et al. The prevalence and morbidity of chronic fatigue and chronic fatigue syndrome: a prospective primary care study. Am J Public Health 1997;87: 1449-55.

14 Powell P, Edwards RHT, Bentall RP. The treatment of wheelchair-bound chronic fatigue syndrome patients: two case studies of a pragmatic rehabilitation approach. Behav Cognitive Psychother 1999;27:249-60.

15 Essame CS, Phelan S, Aggett P, et al. Pilot study of a multidisciplinary inpatient rehabilitation of severely incapacitated patients with the chronic fatigue syndrome. J Chronic Fatigue Syndr 1998:4:51-60.

16 Chalder T, Butler S, Wessely S. In-patient treatment of chronic fatigue syndrome. Behav Cognitive Psychother 1996;24:351-65.

17 NHS Centre for Reviews and Dissemination. Cardiac rehabilitation. Effective Health Care 1998:4.

18 NHS Centre for Reviews and Dissemination. Acute and chronic low back pain. Effective Health Care 2000;6.

19 Sharpe M, Hawton K, Simkin S, et al. Cognitive behaviour therapy for the chronic fatigue syndrome: a randomised controlled trial. BM 1996;312:22-6.

20 Deale A, Chalder T, Marks I, et al. Cognitive behavior therapy for chronic fatigue syndrome: a randomized controlled trial. Am J Psychiatry 1997; 154:408-14

21 Prins J, Bleijenberg G, Bazelmans E, et al. Cognitive behaviour therapy for chronic fatigue syndrome: a multicentre randomised controlled trial. Lancet 2001;357:841-8.

22 Lloyd AR, Hickie I, Brockman A, et al. Immunologic and psychologic therapy for patients with chronic fatigue syndrome: a double-blind, placebo-controlled trial. J Med 1993;94:197-203.

23 Deale A, Hussain K, Chalder T, et al. Long term outcome of cognitive behaviour therapy versus relaxation for chronic fatigue syndrome: a 5-year follow-up study. Am J Psychiatry 2000;158:2038-42

24 O'Dowd H. Cognitive behavioural therapy (CBT) in chronic fatigue syndrome (CFS): a randomised controlled trial of a group prgramme for the primary care population. Available from: http:// www.update-software.com/nrr/CLIBINET.EXE?A $=1 \& U=1001 \& P=10001$ (accessed 23 April 2002)

25 Wessely S. A randomised controlled trial of CBT for CFS in primary care. Available from: http://www.update-software.com/nrr/ CLIBINET.EXE?A=1\&U=1001\&P=10001 (accessed 23 April 2002).

26 Fulcher KY, White PD. Randomised controlled trial of graded exercise in patients with the chronic fatigue syndrome. BM 1997;314:1647-52.

27 Powell P, Bentall RP, Nye FJ, et al. Randomised controlled trial of patient education to encourage graded exercise in chronic fatigue syndrome. BN 2000;322:387-92.

28 Wearden AJ, Morriss RK, Mullis R, et al. Randomised, double-blind placebo-controlled treatment trial of fluoxetine and graded exercise for chronic fatigue syndrome. Br J Psychiatry 1998;172:485-92.

29 Lloyd A, Hickie I, Wakefield D, et al. A double-blind, placebo-controlled trial of intravenous immunoglobulin therapy in patients with chronic fatigue syndrome. Am J Med 1990;89:561-8.

30 Peterson PK, Shepard J, Macres M, et al. A controlled trial of intravenous immunoglobulin $G$ in chronic fatigue syndrome. Am J Med 1990;89:554-60.

31 Rowe KS. Double-blind randomized controlled trial to assess the efficacy of intravenous gammaglobulin for the management of chronic fatigue syndrome in adolescents. J Psychiatr Res 1997;31:133-47.

32 DuBois RE. Gamma globulin therapy for chronic mononucleosis syndrome. AIDS Res 1986;2:S191-5.
33 Vollmer Conna U, Hickie I, Hadzi Pavlovic D, et al. Intravenous immunoglobulin is ineffective in the treatment of patients with chronic fatigue syndrome. Am J Med 1997; 103:38-43.

34 Strayer DR, Carter WA, Brodsky I, et al. A controlled clinical trial with a specifically configured RNA drug, poly(l) $\cdot \operatorname{poly}(\mathrm{C}-12 \mathrm{U})$, in chronic fatigue syndrome. Clin Infect Dis 1994; 1 :S88-95

35 Steinberg P, McNutt BE, Marshall P, et al. Double-blind placebo-controlled study of the efficacy of oral terfenadine in the treatment of chronic fatigue syndrome. J Allergy Clin Immunol 1996:97:119-26.

36 Brook M, Bannister B, Weir W. Interferon-alpha therapy for patients with chronic fatigue syndrome. J Infect Dis 1993;168:791-2.

37 See DM, Tilles JG. Alpha interferon treatment of patients with chronic fatigue syndrome. Immunol Invest 1996;25:1-2.

38 Straus SE, Dale JK, Tobi M, et al. Acyclovir treatment of the chronic fatigue syndrome. Lack of efficacy in a placebo-controlled trial. N Engl J Med 1988:319:1692-8.

39 Lerner AM, Zervos $\mathrm{M}$, Chang $\mathrm{CH}$, et al. A small, randomized, placebo-controlled trial of the use of antiviral therapy for patients with chronic fatigue syndrome. Clin Infect Dis $2001 ; 32: 1657-8$

40 Natelson BH, Cheu J, Pareja J, et al. Randomized, double-blind, controlled placebo-phase in trial of low dose phenelzine in the chronic fatigue syndrome. Psychopharmacology (Berl) 1996;1 24:226-30.

41 Vercoulen JHMM, Swanink CMA, Zitman FG, et al. Randomised double-blind, placebo-controlled study of fluoxetine in chronic fatigue syndrome. Lancet 1996;347:858-61

42 Hickie I, Wilson A, Wright J. A randomised, double blind placebo controlled trial of moclobemide in patients with chronic fatigue syndrome. J Clin Psychiatry 2000;61:643-8.

43 Cleare AJ, Heap E, Malhi GS, et al. Low-dose hydrocortisone in chronic fatigue syndrome: a randomised crossover trial. Lancet 1999;353:455-8

44 McKenzie R, O'Fallon A, Dale J, et al. Low-dose hydrocortisone for treatment of chronic fatigue syndrome: a randomized controlled trial. JAMA 1998;280:1061-6.

45 Peterson PK, Pheley A, Schroeppel J, et al. A preliminary placebo-controlled crossover trial of fludrocortisone for chronic fatigue syndrome. Arch Intern Med 1998;158:908-14.

46 Rowe P, Calkins H, DeBusk K, et al. Fludrocortisone acetate to treat neurally mediated hypotension in chronic fatigue syndrome: a randomized controlled trial. JAMA 2001;285:52-9.

47 Snorrason E, Geirsson A, Stefansson K. Trial of a selective acetylcholinesterase inhibitor, galanthamine hydrobromide, in the treatment chronic fatigue syndrome and related disorders. J Chronic Fatigue Syndr 1995;2:2-3.

48 Tiev KP, Cabane J, Imbert JC. Treatment of chronic postinfectious fatigue: randomized double-blind study of two doses of sulbutiamine (400-600 $\mathrm{mg} /$ day) versus placebo. Rev Med Interne 1999;20:912-8.

49 Moorkens G, Wynants H, Abs R. Effect of growth hormone treatment in patients with chronic fatigue syndrome: a preliminary study. Growth Horm IGF Res 1998:8:131-3.

50 Forsyth LM, Preuss HG, MacDowell AL, et al. Therapeutic effects of oral $\mathrm{NADH}$ on the symptoms of patients with chronic fatigue syndrome. Ann Allergy Asthma Immunol 1999;82:185-91.

51 Warren G, McKendrick $M$, Peet $M$. The role of essential fatty acids in chronic fatigue syndrome: a case-controlled study of red-cell membrane essential fatty acids (EFA) and a placebo-controlled treatment study with high dose of EFA. Acta Neurol Scand 1999;99:112-6.

52 Behan PO, Behan WM, Horrobin D. Effect of high doses of essential fatty acids on the postviral fatigue syndrome. Acta Neurol Scand 1990;82:209-16.

53 Cox IM, Campbell M, Dowson D. Red blood cell magnesium and chronic fatigue syndrome. Lancet 1991;337:757-60

54 Kaslow JE, Rucker L, Onishi R. Liver extract-folic acid-cyanocobalamin vs placebo for chronic fatigue syndrome. Arch Intern Med 1989;149:2501-3

55 Stewart W, Rowse C. Supplements help ME says Kiwi study. J Alterna Complement Med 1987;5:19-20, 2

56 Field TM, Sunshine W, Hernandez Reif M, et al. Massage therapy effects on depression and somatic symptoms in chronic fatigue syndrome. J Chronic Fatigue Syndr 1997;3:43-51

57 Awdry R. Homeopathy may help ME. Int J Alternat Complement Med 1996;14:12-6.

58 Weatherley-Jones E, Thomas K, Nicholl J. Chronic fatigue syndrome: is homeopathic treatment worthwhile? A randomised, controlled trial of individualised treatment vs placebo. Proceedings of the ISHTAC Conference, Philadelphia, 2001

59 Teitelbaum JE, Bird B, Greenfield RM, et al. Effective treatment of chronic fatigue syndrome and fibromyalgia: a randomized, double-blind, placebo-controlled, intent-to-treat study. J Chronic Fatigue Syndr 2001:8:3-28

60 Chalder T. Family focused cognitive behaviour therapy for adolescents with chronic fatigue syndrome: a randomised controlled trial. Available from: http://www.update-software.com/nrr/ CLIBINET.EXE?A=1\&U=1001\&P=10001 (accessed 23 April 2002). 